\section{Category}

Synthesis of Natural Products and

Potential Drugs

\section{Key words}

artemisinin

malaria

amorpha-4,11-

diene

dihydroartemisinic acid
J. CHERRY*, A. KUMAR* ET AL. (IPCA LABORATORIES LIMITED, MUMBAI, INDIA AND AMYRIS INC., EMERYVILLE, USA)

Amalgamation of Synthetic Biology and Chemistry for High-Throughput Nonconventional Synthesis of the Antimalarial Drug Artemisinin

Org. Process Res. Dev. 2017, 21, 551-558.

\title{
Synthesis of Artemisinin
}

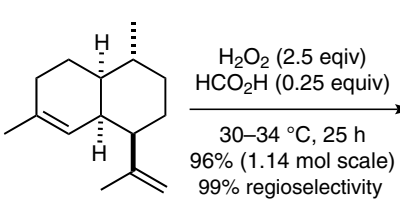

A

amorpha-4,11-diene<smiles>C=C(C)C1CCC(C)C2CCC3(C)OC3C12</smiles>

B<smiles>C=C(CCl)C1CC[C@@H](C)[C@H]2CCC3(C)OC3[C@H]12</smiles>

$\mathrm{K}_{2} \mathrm{HPO}_{4}(2.5$ equiv) $\overrightarrow{D M S O}, 85^{\circ} \mathrm{C}, 45 \mathrm{~h}$ $95 \%$

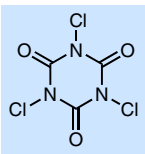

c
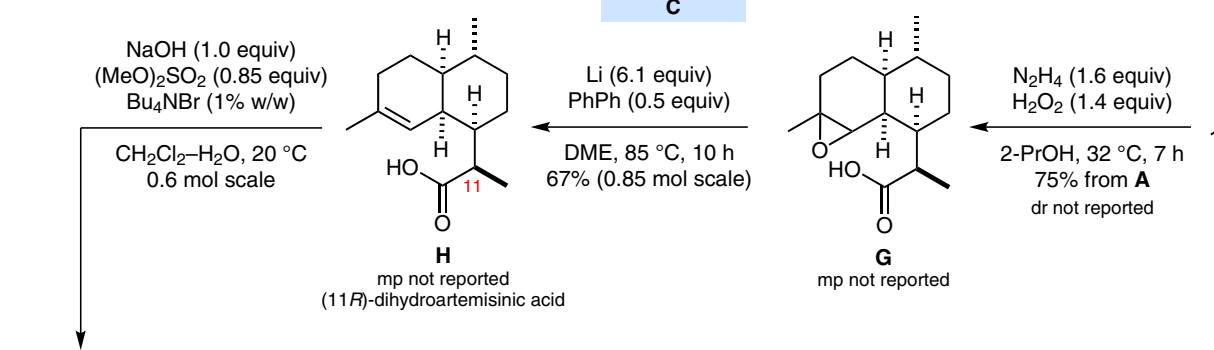<smiles>C=C(C=O)C1CC[C@H](C)[C@H]2CCC3(C)OC3[C@H]12</smiles>

E

$\mathrm{NaClO}_{2}$ (1.1 equiv) $\mathrm{H}_{2} \mathrm{NCO}_{3} \mathrm{H}$ (0.36 equiv) 2-PrOH- $\mathrm{H}_{2} \mathrm{O}, 0^{\circ} \mathrm{C}$

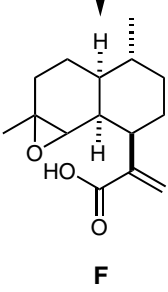

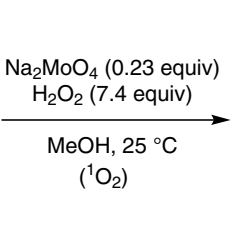

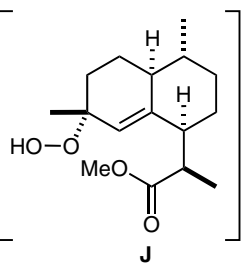

$\mathrm{PhSO}_{3} \mathrm{H}$ ( 0.06 equiv) Indion $225 \mathrm{H}$ resin $(22.32 \mathrm{~g})$ $\mathrm{CH}_{2} \mathrm{Cl}_{2}, 0^{\circ} \mathrm{C}$ to r.t., $25 \mathrm{~h}$ $60 \%$ from $\mathbf{H}$

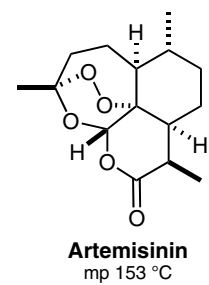

Significance: Artemisinin is extracted from the Chinese medicinal plant Artemisia annua and is used in combination therapy for the treatment of malaria. To date, extraction and total synthesis have failed to address the problems of high cost and erratic supply of artemisinin. Amorpha-4,11diene $(\mathbf{A})$ is a biogenetic precursor of artemisinin that can be generated in titers of more than $120 \mathrm{~g} / \mathrm{L}$ using an engineered yeast strain containing the requisite Artemisia annua genes coupled with an upregulated terpene pathway. The scheme depicts a nine-step conversion of $\mathbf{A}$ into artemisinin in $30 \%$ overall yield.
Comment: The strategy for converting the amorpha-4,11-diene into artemisinin via key intermediate $(11 R)$-dihydroartemisinic acid required the selective functionalization of the exocyclic alkene. Because this was not possible, the more reactive endocyclic alkene was selectively protected as epoxide B. After side-chain manipulation, the epoxide deprotection $(\mathbf{G} \rightarrow \mathbf{H}$ ) was accomplished by reductive elimination using lithium biphenylide - a step that may be challenging on scale.

SYNFACTS Contributors: Philip Kocienski 